\title{
Job Complexity Effect on Job Outcomes: The Role of Positive Core Self-Evaluations as Moderator
}

\section{Amber Jamil1, Dr. Tasneem Fatima ${ }^{2}$ and Dr. Bilal Mirza ${ }^{3}$}

\begin{abstract}
This paper examined the moderating effect of positive core self-evaluations in the job complexity and job outcomes (i.e., job satisfaction, job performance and job creativity) relationship using a sample of 295 workers from various public and private sector organizations in Pakistan. The results show that a positive relationship is found between job complexity with job satisfaction, job performance, and job creativity. The positive core self-evaluations moderated the job complexity and the job outcomes (job satisfaction and job creativity) relationship where it further strengthened the positive relationship of job complexity with these outcomes. However, the positive core self-evaluations did not moderate the job complexity and the job performance relationship. The results suggests that individuals having elevated CSE due to positive self-evaluations respond more positively to the challenge stressor of JC and tend to become not only more satisfied from their jobs but also become more creative in their jobs.
\end{abstract}

Keywords: Job complexity; positive CSE; job satisfaction; job performance; job creativity;

JEL Codes: D23, J28, M12

\footnotetext{
${ }^{1}$ Assistant Professor, (FMS), International Islamic University Islamabad (IIUI)

${ }^{2}$ Assistant Professor/Chairperson Women Campus , (FMS), International Islamic University Islamabad (IIUI)

${ }^{3}$ Assistant Professor, UCP Business School, University of Central Punjab (UCP)
} 